\section{Rethink dental electives}

Sir, dental education has not been spared from the considerable and irrefutable damage caused by the COVID-19 pandemic. Dental electives have become a tradition for dental students in the UK when they spend some time in the summer, usually ranging from two weeks to one month, in a country of their choice learning more about a particular field of dentistry.

That being said, the pandemic has fostered various alternative forms of learning. While students are unable to benefit from the dental elective experience this year, they have been able to utilise many alternative online resources. This has encouraged and enabled students to take a more proactive approach in pursuing their areas of interest, rather than just being limited to the generic top-down learning approaches. Online learning provides greater flexibility for the students to learn in a way that works for them.

While COVID-19 has resulted in the cancellation of dental electives, the rise of virtual electives begs the question of where the true value of dental electives lie. Both students and educators must consider how elective-related resources should be allocated and where dental students should be placed so as to achieve maximum student, and ultimately societal, benefit.

C. W. N. Liu, London, UK https://doi.org/10.1038/s41415-020-2072-y

\section{PPE: a coin with two sides}

Sir, in order to provide safe dental services, the NHS recommends strict personal protective equipment (PPE) which includes N95 (FFP2) respirator, impermeable full sleeved gown and face shield. ${ }^{1}$ Recently, additional literature has suggested that these strict PPE requirements impair the technical and non-technical skills of health professionals. $^{2}$

We completed a questionnaire-based study at our dental clinics in the Aga Khan University with oxygen saturation and pulse rates assessed in 35 staff members. The results were in line with the study conducted by Yánez et al. ${ }^{2}$ who suggested impaired visibility and communication, increased fatigue, headache and dissatisfaction with work. Furthermore, there was a statistically significant drop in oxygen saturation and increase in pulse rate after wearing PPE for four hours as compared to baseline.

Another finding was that most of the participants tended to adjust their N95 mask intermittently for breathing issues which raised the risk of selfcontamination. ${ }^{3}$ How long this pandemic may last is anybody's guess and therefore the strict PPE requirements are unlikely to change soon. Consequently, we recommend further studies are required to observe the long-term effect of PPE on the general health of the wearer.

F. Umer, K. Devi, S. Jamal, Karachi, Pakistan

\section{References}

1. Press release. New personal protective equipment (PPE) guidance for NHS teams. 2 April 2020. Available at: https://www.gov.uk/government/ news/new-personal-protective-equipment-ppeguidance-for-nhs-teams (accessed August 2020).

2. Yánez Benítez C, Güemes A, Aranda J et al. Impact of personal protective equipment on surgical performance during the COVID-19 pandemic. World J Surg 2020; 44: 2842-2847.

3. Umer F, Haji Z, Zafar K. Role of respirators in controlling the spread of novel coronavirus (COVID19) amongst dental healthcare providers: a review. Int Endod J 2020; 53: 1062-1067.

https://doi.org/10.1038/s41415-020-2078-5

\section{Remote GDC hearings}

Sir, in these sombre times one significant outcome for the regulation of dentistry has been the rapid development of effective measures and an acceptance of the novel means enabling hearings to continue remotely and efficiently. In response to COVID-19, the Lord Chief Justice (LCJ) stated the courts must not grind to a halt and with a remarkable degree of cooperation, great strides followed decades of stagnation in the administration of justice. $^{1}$

In the absence of any framework, consideration of the following steps may assist those participating in remote GDC proceedings:

1. Appropriateness. Can the matter be decided in a way other than remotely, live or resolved on the papers alone and can witness support and protection still be assured?

2. Application. A formal request may be needed with skeleton arguments providing references to case and law relevant to deciding the matter
3. Apparatus. A secure audio-visual link requires prior testing, often across vast distance and different time zones

4. Access. A Scott Schedule of enumerated documents needs to be agreed, accessible and available to all in advance

5. Affirmation. When giving live evidence remotely an oath is taken.

With respect to the last step, while the 2020 Coronavirus Act expands the realm and reach of the justice system into the comfort of one's own surroundings, the foundation upon which this latest legislation is built rests upon established law. Not least is the 1911 Perjury Act. Finding that a failure to be truthful was deliberate could result in a custodial sentence. We hope these five steps benefit those preparing for and participating in GDC remote hearings. The numbers of those now taking place with greater ease and efficiency may soon begin to rise again.

J. Laszlo, London, E. Mills, Truro, UK

\section{Reference}

1. Ames J. Lord Burnett, the lord chief justice, hails courts' tech solution to coronavirus crisis. The Times Thursday 9 April 2020. Available at: https://www. thetimes.co.uk/article/lord-burnett-the-lord-chiefjustice-hails-courts-tech-solution-to-coronaviruscrisis-7gp3qd06g (accessed August 2020).

https://doi.org/10.1038/s41415-020-2077-6

\section{Question time}

Sir, at the present time in dentistry, in response to the pandemic, I think we need to ask ourselves three fundamental questions:

- Was dentistry safe and has it become dangerous?

- Was dentistry complex and will it become more simple?

- Was dentistry effective and will it become less effective?

These questions were posed originally by Jane Dacre President of the Royal College of Physicians in 2017 in relation to medicine and used by myself in a presentation to the local BDA Group in Nottingham later that year in September 2017.

P. Ward, Nottingham, UK https://doi.org/10.1038/s41415-020-2079-4 